\title{
24. EXPERIMENTAL EMPLACEMENT MODE DETERMINATION OF BASALT IN HOLE 396B
}

\author{
Brooks B. Ellwood ${ }^{1}$ and Norman D. Watkins, Graduate School of Oceanography, \\ University of Rhode Island, Kingston, Rhode Island
}

\begin{abstract}
The anisotropy of magnetic susceptibility (AMS) and remanent magnetism of 32 basaltic samples from Hole 396B have been measured.

Using criteria developed in our earlier studies of DSDP basaltic rocks, the AMS data suggest a definite extrusive origin for all samples except those in the 235 to 244 meter depth interval, where an intrusive body may have been sampled.

We have now measured the AMS of 246 basaltic samples taken from the first 46 legs of DSDP. One-third of these have been diagnosed as intrusive. Shallower parts of Layer 2 appear to have a higher intrusive fraction than is the case for ophiolite complexes.
\end{abstract}

\section{INTRODUCTION}

Kidd (1976) and Kidd and Vine (1976) have recently emphasized the importance of emplacement mode determinations of igneous samples in defining the structure of the oceanic crust. Without such control, the direct testing of their new linear magnetic anomaly formation models would be perhaps impossible. Ellwood and Watkins (1976) have shown that emplacement mode analyses of DSDP samples is possible if a sufficiently large data set is available. During the earliest phases of DSDP, it became clear that conventional means of distinguishing between intrusive and extrusive igneous rocks would, for a range of reasons, not be feasible to any consistent extent. For this reason we initiated experimental attempts to solve the problem (Ellwood and Watkins, 1973). The principle which we have employed is based on the suspicion that pressure fields present during emplacement would be more systematic for intrusive rocks, so that net preferred elongation of crystals can be expected to be higher in intrusives. We have used anisotropy of magnetic susceptibility (AMS) measurements to measure variations in the net preferred elongation of ferrimagnetic crystals in unaltered DSDP basaltic rocks.

Magnetic susceptibility $(K)$ is a proportionality constant relating the intensity of magnetization which is induced in a sample by placing it in a given magnetic field. It is a tensor of the second rank and is usually characterized by a representation quadric whose maximum, intermediate, and minimum orthogonal axial magnitudes are $K_{a}, K_{b}$, and $K_{c}$, respectively. For most materials the axial magnitudes are similar (the material is nearly isotropic). When basalts contain crystals with a slight degree of preferred alignment, the axes are unequal, and such anisotropy can be measured. The triaxial ellipsoid which can be derived from AMS measurements describes the directions and magnitudes of each axis. Ellwood (1975) observed that various functions of AMS differed between samples because of contrasts in the mea-

\footnotetext{
${ }^{1}$ Present address: Dept. of Geology, University of Georgia, Athens, Georgia.

${ }^{2}$ Now deceased.
}

sured $K$. He therefore suggested the use of an emplacement mode indicator $F$, where

$$
F=\frac{K a^{\prime}}{\left(K b^{\prime} \times K c^{\prime}\right)^{1 / 2}}
$$

and $K_{a}{ }^{\prime}, K b^{\prime}$, and $K_{c}{ }^{\prime}$ are tensor magnitudes recalculated for a standard volume susceptibility of $1.0 \times 10^{-3}$ cgs. units. $F$ emphasizes long axis alignments and is independent of $K$. Ellwood (1975) measured 312 specimens from known intrusive and extrusive units and showed that a value of $F=1.04$ divides, with 80 per cent confidence, intrusives from extrusives.

While believing that directions of remanent magnetism in DSDP basalts are of limited value, we also measure the remanent magnetic properties for use in inferring titanomagnetite oxidation state, crystal size, and stability (Watkins and Haggerty, 1967). Although not invariably true, magnetic stability tends to be higher in extrusives, because of faster cooling rates and higher oxidation states, which produce smaller effective titanomagnetite crystal size.

We have measured (Ellwood and Watkins, 1975) a large collection of DSDP igneous rocks, and showed that emplacement mode is between 20 and 40 per cent intrusive. This paper is part of a series in which we continue to add to the data, which we ultimately hope to use for characterizing the rate of increase of intrusive fraction with depth in the ocean crust.

\section{METHODS}

A total of 32 samples of $2.5-\mathrm{cm}$ diameter were drilled normal to the vertical axis of the basaltic core recovered at Hole 396B on DSDP Leg 46. Sample depth in the core ranged from 157 to 359 meters below the sea floor. Samples were sliced into cores of 2.2-cm length. AMS was measured on a low-field torque meter similar to that described by Stone (1963). $K$ was measured using a $300 \mathrm{~Hz}$ susceptibility bridge (Collinson et al., 1963). Precision limits have been described by Ellwood (1975). 


\section{RESULTS}

The AMS results for all samples are given in Table 1. The ratio of the intensity of magnetization before and after demagnetization in peak alternating fields of 100 and $200 \mathrm{Oe}$ is included in the table.

\section{DISCUSSION}

\section{Emplacement Mode in Hole 396B}

The last column of Table 1 indicates the emplacement mode inferred from the measured $F$ values. It can be seen that $F$ for all except one sample is well below 1.04, consistent with a nearly isotropic net crystal arrangement. At 237.7 meters depth below the mudline, one sample occurs with a slightly anisotropic quality: conceivably, then, an intrusive body has been sampled.

Functions of stability of the remanent magnetism $\left(J_{100} / J_{0}\right.$ and $J_{200} / J_{0}$, where $J=$ intensity of magnetization and the suffixes refer to the peak demagnetizing field in Oe, with $o$ $=$ the undemagnetized specimen) show that almost all samples retained more than 70 per cent of their original $J$ after demagnetization at $200 \mathrm{Oe}$. The lowest $J$ retained after demagnetization is 23 per cent, and occurs at a depth of 237.7 meters. Therefore, the sample at this depth has two properties which are consistent with an intrusive origin.

\section{Emplacement Mode for All DSDP Igneous Rocks}

It is appropriate to review all our results to date. Figure 1 illustrates $F$ values determined for all 246 DSDP samples which we have measured. The samples are from Holes 10, $57,63,66,105,146,163,165 \mathrm{~A}, 304,317 \mathrm{~A}, 319 \mathrm{~A}, 321$, $332 \mathrm{~B}, 334,335$, and 396B. The depths in each hole are given in Table 2 .

In Figure 2 we illustrate a comparison of the $F$ value emplacement mode determinations with determinations made by conventional means during the respective cruises, as reported in the Initial Reports volumes. The results are also summarized in Table 2. Total disagreement between the independent emplacement mode determinations occurs only for Hole 63. Such a disagreement could be of substan- tial significance. For example, the age of the sea-level magnetic anomaly above the hole may be inferred from micropaleontological analysis of the oldest sediment in the hole. If the hole were terminated in a sill within Layer 1, then the age of basement could be much younger than the age of the material causing the anomaly.

The overall extrusive to intrusive ratio in the shallower portions of Layers 1 and 2 of the oceanic crust is illustrated in Figure 3 and suggests that extrusives dominate over intrusives by a 2 to 1 ratio. The high percentage of intrusives is similar to results reported for 180 DSDP samples by Ellwood and Watkins (1976), who have pointed out that such high intrusive percentages are not found in the shallower parts of ophiolite sequences. Intrusions into Layer 1 sediments could in part account for this observation, but it is now appearing that the sea floor may be characterized by intrusive fractions which are higher than expected.

\section{REFERENCES}

Collinson, D.W., Stone, D.B., and Molyneux, L., 1963. A total and anisotropicmagnetic susceptibility meter, J. Sci. Instrum., v. 40 , p. $310-312$.

Ellwood, B.B., 1975. Analysis of emplacement mode in basalt from DSDP Holes 319A and 321 using anisotropy of magnetic susceptibility, J. Geophys. Res., v. 80, p.4805-4808.

Ellwood, B.B. and Watkins, N.D., 1976. Comparison of observed intrusive to extrusive ratios in Iceland and the Troodos Massif with results of experimental emplacement mode analysis of DSDP igneous rocks, J. Geophys. Res. v. 81, p.4152-4156.

Kidd, R.G.W., 1976. The shape and nature of the sources of marine magnetic anomalies, EOS Am. Geopys. Un. Trans. v. 57 , p. 655 .

Kidd, R.G.W. and Vine, F.J., 1976. Some effects of a proposed shape for marine magnetic anomaly source blocks, Programme: Third European Geophysical Society Meeting, p. 12.

Stone, D.B., 1963. Anisotropic magnetic susceptibility measurements on a phonolite and on a folded metamorphic rock, Geophys. J. v. 7, p. 375-390.

Watkins, N.D. and Haggerty, S.E., 1967. Primary oxidation variation and petrogenesis on a single lava, Contrib. Mineral. Petrol., v. 15, p. 251-271. 
TABLE 1

Anisotropy of Magnetic Susceptibility Data for Basaltic Samples From Hole 396B, DSDP Leg 46

\begin{tabular}{|c|c|c|c|c|c|c|c|c|c|c|c|c|c|c|c|c|}
\hline $\begin{array}{c}\text { Sample } \\
\text { (Interval in } \mathrm{cm} \text { ) }\end{array}$ & $\begin{array}{l}\text { Depth } \\
(\mathrm{m})\end{array}$ & $\mathrm{K} \times 10^{-4}$ & ${ }^{\mathrm{J}_{100}} / \mathrm{J}_{\mathrm{nrm}}$ & $\mathrm{J}_{200} / \mathrm{J}_{\mathrm{nrm}}$ & $\mathrm{K}_{\mathrm{a}} \times 10^{-4}$ & $\mathrm{~K}_{\mathrm{b}} \times 10^{-4}$ & $\mathrm{~K}_{\mathrm{c}} \times 10^{-4}$ & $\mathrm{D}_{\max }$ & $\mathrm{I}_{\max }$ & $\mathrm{D}_{\text {int }}$ & $\mathrm{I}_{\text {int }}$ & $\mathrm{D}_{\min }$ & $I_{\min }$ & $\% \mathrm{An}$ & $\mathrm{F}$ & "Emplacement" \\
\hline $5-1,34$ & 157.34 & 1.423 & 0.903 & 0.796 & 1.432 & 1.421 & 1.417 & 208.3 & -21.7 & 104.5 & -30.9 & 327.5 & -50.7 & 1.063 & 1.001 & E \\
\hline $5-1,60$ & 157.60 & 1.981 & 0.823 & 0.625 & 1.995 & 1.987 & 1.961 & 327.8 & -0.7 & 237.2 & -42.1 & 58.6 & -44.9 & 1.718 & 1.002 & E \\
\hline $5-2,54$ & 159.04 & 1.105 & 0.935 & 0.791 & 1.117 & 1.103 & 1.094 & 163.8 & -9.1 & 286.8 & -73.5 & 71.6 & -13.6 & 2.100 & 1.002 & E \\
\hline $7-1,65$ & 174.65 & 1.200 & 0.838 & 0.681 & 1.211 & 1.203 & 1.187 & 356.7 & -14.4 & 260.3 & -23.5 & 114.4 & -61.9 & 1.947 & 1.002 & $\mathrm{E}$ \\
\hline $8-1,69$ & 184.19 & 1.013 & 0.907 & 0.677 & 1.034 & 1.012 & 0.992 & 289.7 & -36.5 & 179.2 & -25.3 & 63.1 & -42.9 & 4.135 & 1.003 & E \\
\hline $9-1,88$ & 193.88 & 1.232 & 0.760 & 0.531 & 1.239 & 1.235 & 1.223 & 217.0 & -29.5 & 114.9 & -20.6 & 354.8 & -53.0 & 1.334 & 1.001 & E \\
\hline $9-2,127$ & 195.77 & 0.519 & 0.935 & 0.910 & 0.522 & 0.520 & 0.515 & 277.6 & -24.2 & 12.9 & -11.4 & 126.1 & -62.9 & 1.324 & 1.000 & E \\
\hline $10-2,30$ & 204.30 & 0.559 & 0.969 & 0.823 & 0.567 & 0.558 & 0.553 & 109.1 & -46.7 & 293.9 & -43.2 & 201.7 & -2.4 & 2.380 & 1.001 & E \\
\hline $11-1,134$ & 213.34 & 1.010 & 0.893 & 0.766 & 1.026 & 1.005 & 1.000 & 173.6 & -42.4 & 168.2 & -5.1 & 3.7 & -47.2 & 2.675 & 1.002 & E \\
\hline $12-1,61$ & 215.11 & 1.165 & 0.801 & 0.632 & 1.179 & 1.171 & 1.147 & 136.9 & -12.6 & 235.2 & -32.7 & 28.8 & -54.3 & 2.799 & 1.002 & $\mathrm{E}$ \\
\hline $13-1,63$ & 217.13 & 1.232 & 0.844 & 0.626 & 1.265 & 1.219 & 1.212 & 256.1 & -41.7 & 21.4 & -38.5 & 132.4 & -24.3 & 4.360 & 1.005 & E \\
\hline $14-2,42$ & 226.40 & 0.833 & 0.974 & 0.797 & 0.873 & 0.842 & 0.785 & 344.4 & -52.1 & 169.9 & -37.8 & 77.8 & -2.7 & 10.481 & 1.006 & E \\
\hline $14-2,42$ & 227.42 & 0.691 & 0.979 & 0.823 & 0.702 & 0.697 & 0.673 & 162.6 & -8.5 & 252.6 & -0.5 & 345.6 & -81.4 & 4.173 & 1.002 & $\mathrm{E}$ \\
\hline $15-1,100$ & 236.00 & 9.877 & 1.225 & 0.903 & 0.902 & 0.864 & 0.863 & 221.9 & -69.6 & 61.9 & -19.3 & 329.6 & -6.5 & 4.550 & 1.004 & $\mathrm{E}$ \\
\hline $15-2,124$ & 237.74 & 16.340 & 0.668 & 0.232 & 16.702 & 16.268 & 16.056 & 36.1 & -61.8 & 207.3 & -27.9 & 299.3 & -3.7 & 3.975 & 1.067 & I \\
\hline $16-1,76$ & 245.26 & 0.721 & 0.983 & 0.861 & 0.732 & 0.722 & 0.709 & 183.3 & -10.0 & 291.9 & -61.1 & 88.2 & -26.8 & 3.204 & 1.002 & $\mathrm{E}$ \\
\hline $16-5,104$ & 251.54 & 0.486 & 1.009 & 0.964 & 0,488 & 0.485 & 0.483 & 178.8 & -25.6 & 20.8 & -62.7 & 273.1 & -8.9 & 0.997 & 1.000 & $\mathrm{E}$ \\
\hline $17-2,86$ & 269.86 & 0.926 & 0.840 & 0.753 & 0.943 & 0.923 & 0.913 & 211.4 & -27.9 & 10.7 & -60.5 & 115.7 & -8.8 & 3.191 & 1.002 & E \\
\hline $17-3,28$ & 270.78 & 0.914 & 1.007 & 0.777 & 0.949 & 0.909 & 0.885 & 319.5 & -20.8 & 198.4 & -53.7 & 61.3 & -28.3 & 7.050 & 1.005 & E \\
\hline $18-1,108$ & 274.08 & 1.390 & 0.786 & 0.523 & 1.434 & 1.410 & 1.324 & 331.1 & -50.1 & 192.3 & -32.3 & 88.4 & -20.9 & 7.797 & 1.007 & $\mathrm{E}$ \\
\hline $18-2,53$ & 275.03 & 0.672 & 0.994 & 0.924 & 0.683 & 0.668 & 0.666 & 169.4 & -26.8 & 358.4 & -62.9 & 261.2 & -3.6 & 2.504 & 1.002 & E \\
\hline $20-2,25$ & 287.25 & 0.859 & 0.946 & 0.823 & 0.868 & 0.860 & 0.840 & 209.4 & -13.6 & 115.7 & -14.8 & 340.2 & -69.6 & 2.120 & 1.001 & E \\
\hline $20-3,142$ & 290.92 & 0.707 & 0.924 & 0.889 & 0.721 & 0.704 & 0.695 & 327.2 & -4.6 & 236.9 & -2.7 & 116.3 & -84.7 & 3.675 & 1.002 & E \\
\hline $20-4,52$ & 291.52 & 0.852 & 0.944 & 0.845 & 0.869 & 0.847 & 0.841 & 112.3 & -11.0 & 024.4 & -10.7 & 337.5 & -75.6 & 3.322 & 1.003 & E \\
\hline $20-6,45$ & 294.45 & 0.821 & 0.890 & 0.794 & 0.834 & 0.820 & 0.811 & 211.7 & -1.6 & 121.1 & -23.1 & 305.5 & -66.8 & 2.823 & 1.002 & E \\
\hline $21-1,34$ & 296.34 & 1.178 & 0.933 & 0.689 & 1.233 & 1.154 & 1.147 & 228.5 & -20.5 & 122.9 & -35.7 & 342.2 & -47.1 & 7.412 & 1.008 & E \\
\hline $22-1,136$ & 306.86 & 0.985 & 0.957 & 0.910 & 1.035 & 0.969 & 0.950 & 352.6 & -0.6 & 262.4 & -15.5 & 84.7 & -74.5 & 8.714 & 1.007 & E \\
\hline $22-2,48$ & 307.48 & 0.953 & 0.960 & 0.933 & 0.979 & 0.965 & 0.915 & 186.5 & -2.9 & 276.8 & -4.3 & 62.8 & -84.8 & 6.675 & 1.004 & $\mathrm{E}$ \\
\hline $22-3,133$ & 309.83 & 1.075 & 0.983 & 0.800 & 1.093 & 1.067 & 1.065 & 335.6 & -49.5 & 174.7 & -38.9 & 76.9 & -9.5 & 2.683 & 1.003 & E \\
\hline $22-4,13$ & 310.13 & 0.680 & 0.895 & 0.816 & 0.696 & 0.679 & 0.664 & 199.1 & -9.1 & 107.1 & -11.8 & 326.8 & -75.0 & 4.637 & 1.002 & E \\
\hline $23-1,81$ & 315.81 & 1.197 & 0.972 & 0.956 & 1.219 & 1.200 & 1.173 & 103.9 & -8.9 & 237.4 & -77.2 & 12.4 & -9.2 & 3.804 & 1.003 & E \\
\hline $28-1,9$ & 358.09 & 2.460 & 0.289 & 1.043 & 2.541 & 2.426 & 2.412 & 298.7 & -47.8 & 99.8 & -40.6 & 198.1 & -9.5 & 6.332 & 1.012 & E \\
\hline
\end{tabular}

Note: $\mathrm{K}=$ volume susceptibility in cgs units; $\mathrm{K}_{a}, \mathrm{~K}_{\mathrm{b}}, \mathrm{K}_{\mathrm{c}}=$ magnitudes in cgs units of (A) maximum, (B) intermediate, and (C) minimum susceptibility; corresponding directions given by $\mathrm{D}$ and $\mathrm{I}$ max., int., and min., where $\mathrm{D}=$ declination in degrees east of an arbitrary zero azimuth; $\mathrm{I}=$ inclination, \% $\mathrm{An}=$ percent anisotropy $=\left(\mathrm{K}_{\mathrm{a}}-\mathrm{K}_{\mathrm{c}}\right) \mathrm{K}_{\mathrm{b}} \times 100.0 ; \mathrm{F}=\mathrm{emplacement}$ number, see text for definition. "Emplacement": $\mathrm{E}=$ extrusive; $\mathrm{I}=$ intrusive. $\mathrm{J}_{100} / \mathrm{J}_{\mathrm{nrm}}$ and $\mathrm{J}_{200} / \mathrm{J}_{\mathrm{nrm}}$ are simple ratios illustrating intensity of magnetization decrease with demagnetization treatment, where $\mathrm{J}_{\text {nrm }}$, $\mathrm{J}_{100}$ " and $\mathrm{J}_{200}$ are the intensities of magnetization for natural remanent magnetization and after 100 and 200 Oe demagnetization treatments, respectively. 


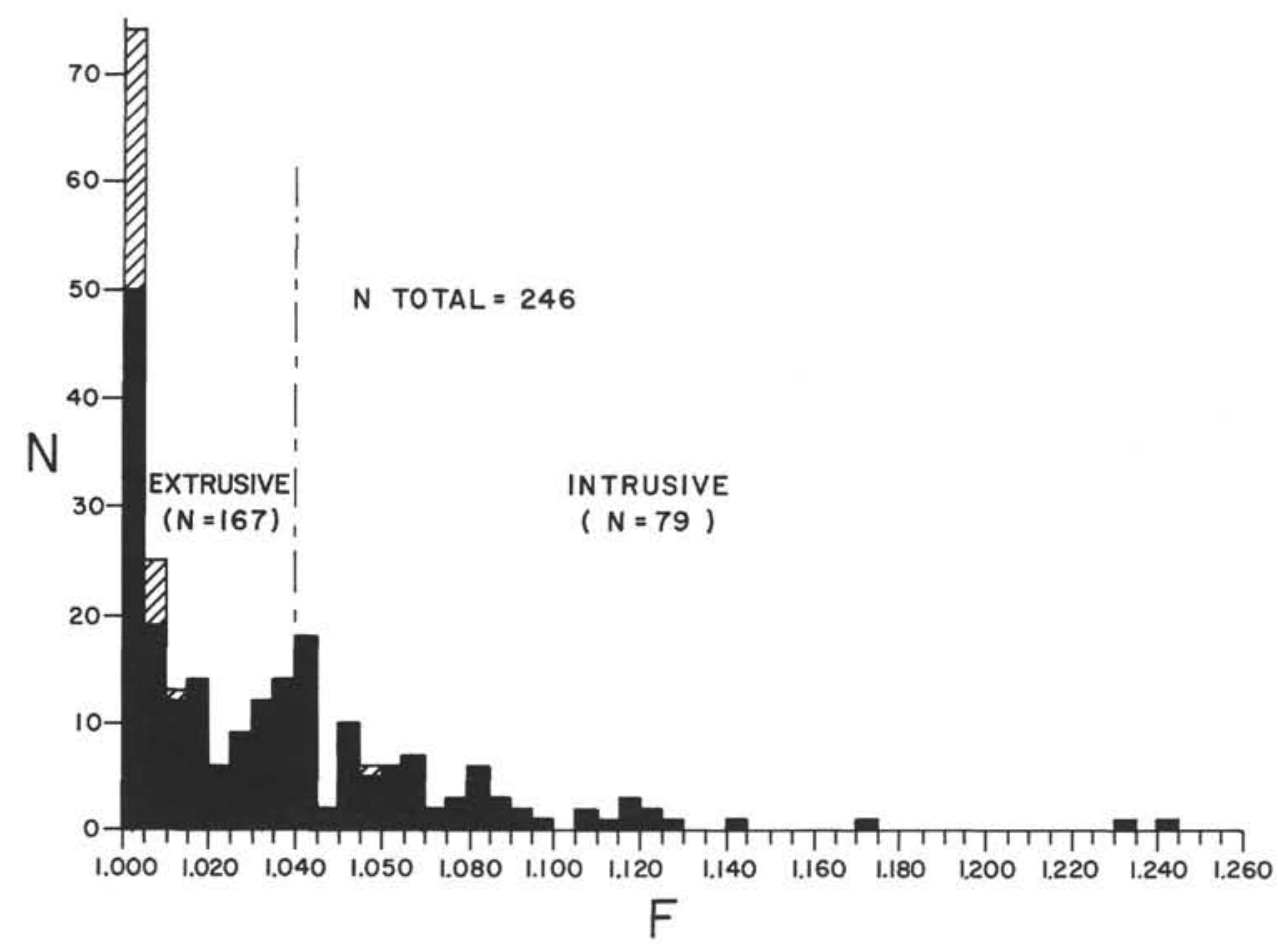

Figure 1. Histogram of $\mathrm{F}$ values in 246 DSDP igneous samples. The dashed line divides "intrusives" (F > 1.040) from "extrusives" (F < 1.040) according to Ellwood (1975). Hatched symbols are from current analyses on Hole 396B. Blackened values are from Holes 10, 57, 63, 66, 105, 146, 163, 165A, 304, 317A, 319A, 321, 332B, 334, and 335 , and represent $\mathrm{F}$ results for all DSDP samples which we have analyzed.

TABLE 2

Comparison of DSDP Basaltic Emplacement Mode Analyses Using Anisotropy of Magnetic Susceptibility and Conclusions Reached in the Initial Reports

\begin{tabular}{|c|c|c|c|c|c|c|c|}
\hline Leg No. & Hole No. & Depth Range (cm) & $\mathrm{N}$ & AMS Emplacement Mode & $\begin{array}{c}\text { Initial Reports } \\
\text { Emplacement Mode }\end{array}$ & $\begin{array}{l}\text { Initial Report } \\
\text { Page No. }\end{array}$ & Remarks from Initial Report \\
\hline 2 & 10 & $459.9-461.1$ & 7 & E. & E & 211.218 & Volcanic assumed to mean extrusive \\
\hline 6 & 57 & $328.9 \cdot 331.4$ & 9 & i & E. 1 & 496 & \\
\hline 7 & 63 & $564.2-565.8$ & 6 & i & $\mathrm{E}$ & 328,329 & Basalt contains xenoliths of baked calcareous sediment \\
\hline 7 & 66 & $192.0-193.0$ & 2 & $\mathrm{E}$ & E & 730 & \\
\hline 11 & 105 & $625,3-632.9$ & 28 & E & $\mathrm{E}$ & 227 & \\
\hline is & 146 & $749.5-758.7$ & 28 & i & I & $17,22,24,26,33$ & \\
\hline 16 & 163 & $276.2-293.8$ & 24 & E & $\mathrm{E}$ & $411,413,416,418$ & \\
\hline 17 & $165 \mathrm{~A}$ & $452.3-489.9$ & 12 & $\mathrm{E}$ & E & $47,59,60,64$ & Interbedded basalts and sediments \\
\hline 32 & 304 & $335.9-344.1$ & 11 & 1 & E, I & 49,55 & \\
\hline 33 & $317 \mathrm{~A}$ & $915.2-943.5$ & 7 & $\mathrm{E}$ & $\mathrm{E}$ & $162.163,170,171,186$ & Interbedded basalts and sediments \\
\hline 34 & $319 \mathrm{~A}$ & $98.4-120.7$ & 17 & E & E. I & 28,34 & Possibly shallow sills \\
\hline 34 & $319 \mathrm{~A}$ & $121.1 \cdot 123.7$ & 5 & 1 & E, 1 & 28,34 & Possibly shallow sills \\
\hline 34 & $319 \mathrm{~A}$ & $123.9-148.0$ & 11 & E & E. i & 28,34 & Possibly shallow sills \\
\hline 34 & 321 & $125.5-129.9$ & 10 & $i$ & E.i & $118,123,124$ & Possibly shallow sills \\
\hline 37 & $332 \mathrm{~B}$ & $156.0-677.0$ & 25 & $\mathrm{E}$ & $\vec{E}$ & 26 & \\
\hline 37 & 334 & $292.5 \cdot 319.5$ & 2 & $\mathrm{E}$ & $\mathrm{E}$ & 63 & \\
\hline 37 & 334 & $321.5-321.9$ & 2 & 1 & 1 & 63 & Not basaltic samples \\
\hline 37 & 335 & $467.0-516.0$ & 8 & E & $\mathrm{E}$ & 74 & \\
\hline 46 & $396 \mathrm{~B}$ & $157.3 \cdot 358.1$ & 32 & $\mathrm{E}$ & $\mathrm{E}$ & $1-14$ & Discussion is in the Igneous and Metamorphic rocks section of report \\
\hline
\end{tabular}

Note: Depth range below the mudline. $n=$ number of samples within each depth range. $\mathrm{E}=$ extrusive and $\mathrm{I}=$ intrusive, refers to the dominant emplacement mode within each depth range. Page numbers are taken from the Site Report portions of the Initial Report for the leg involved. Leg No. = Initial Report Volume No. (Note: at the time of writing, Initial Reports for Legs 37 and 46 had not been published, so page references are from the preliminary green book and orange book, respectively.) 


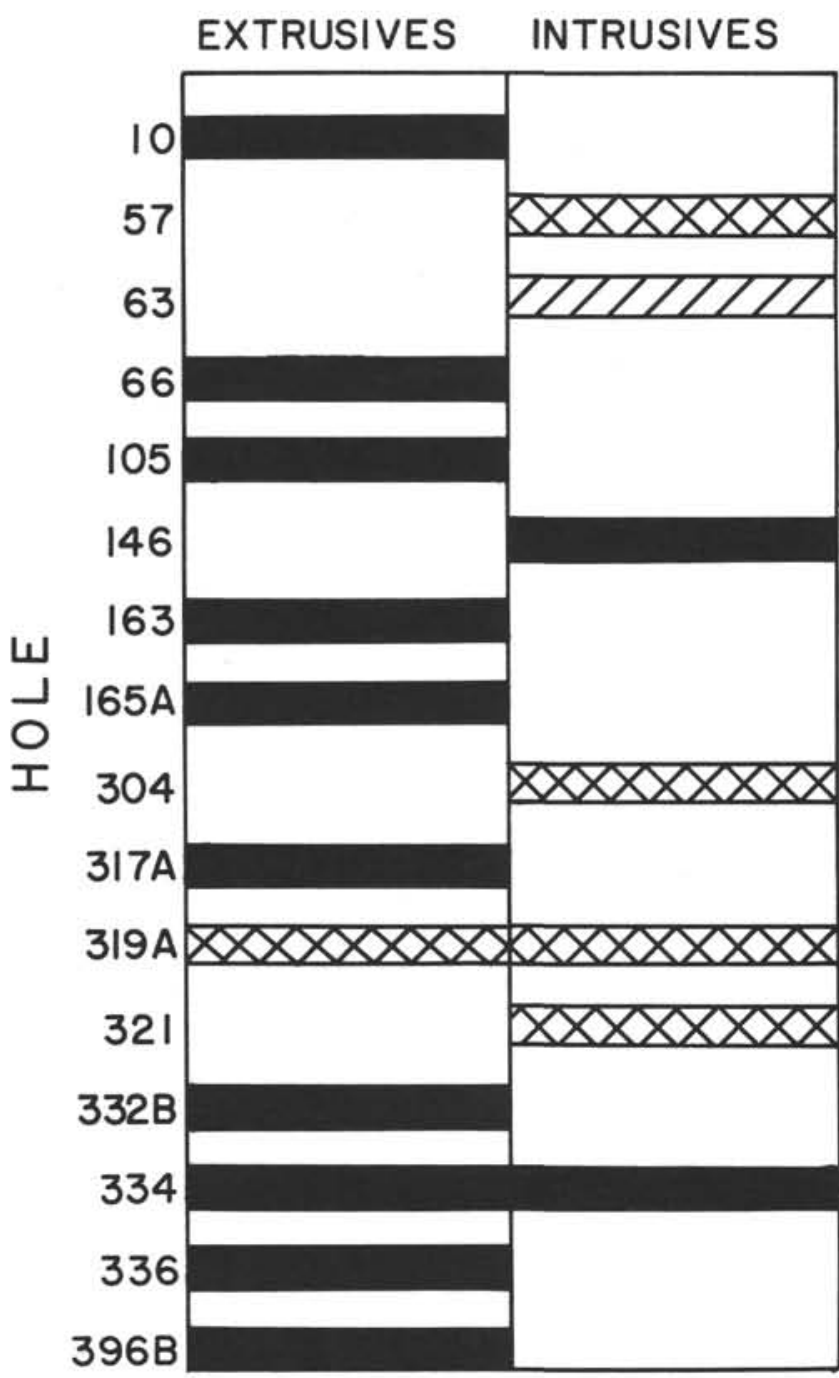

\section{Z7 Disagreement (I) \\ Unknown Emplacement Mode (5) Agreement (I2)}

Figure 2. Comparison of mode of emplacement of DSDP igneous rocks using anistropy of magnetic susceptibility measurements and conventional analyses, as given in the respective Initial Reports volumes for the hole indicated. Black solid bars represent agreement of AMS analyses with Initital Reports. Cross-hatched bars indicate that emplacement mode conclusions in the Initial Reports for the hole represented are in doubt (conclusions for Hole 321 , for example, suggest the basalt may be a shallow sill or a flow). Hatched bars show disagreement of AMS data with conclusions made in the Initial Reports volume. See Table 2 for further details.

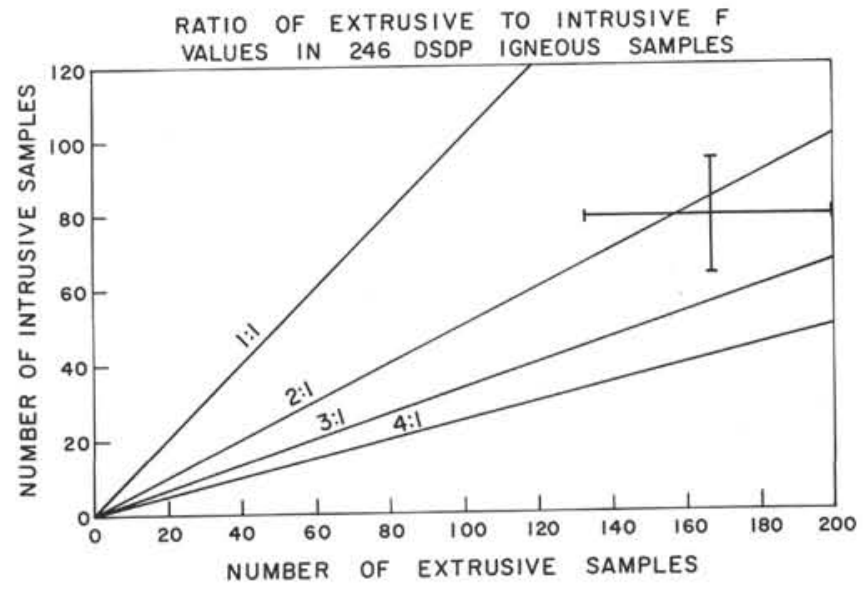

Figure 3. Comparison of intrusive to extrusive samples from DSDP basaltic cores collected during cruises through Leg 46, as determined using anisotropy of magnetic susceptibility measurements. Twenty per cent confidence limits added. 